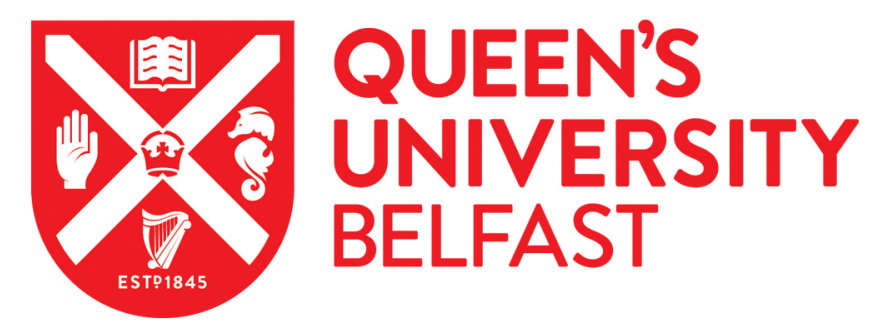

\title{
Potentially inappropriate prescribing among people with dementia in primary care: a retrospective cross-sectional study using the Enhanced Prescribing Database
}

Barry, H. E., Cooper, J. A., Ryan, C., Passmore, A. P., Robinson, A. L., Molloy, G. J., Darcy, C. M., Buchanan, H., \& Hughes, C. M. (2016). Potentially inappropriate prescribing among people with dementia in primary care: a retrospective cross-sectional study using the Enhanced Prescribing Database. Journal of Alzheimer's disease : $J A D, 52(4), 1503-1513$. https://doi.org/10.3233/JAD-151177

Published in:

Journal of Alzheimer's disease : JAD

Document Version:

Peer reviewed version

Queen's University Belfast - Research Portal:

Link to publication record in Queen's University Belfast Research Portal

Publisher rights

Copyright 2016 The Authors

\section{General rights}

Copyright for the publications made accessible via the Queen's University Belfast Research Portal is retained by the author(s) and / or other copyright owners and it is a condition of accessing these publications that users recognise and abide by the legal requirements associated with these rights.

\section{Take down policy}

The Research Portal is Queen's institutional repository that provides access to Queen's research output. Every effort has been made to ensure that content in the Research Portal does not infringe any person's rights, or applicable UK laws. If you discover content in the Research Portal that you believe breaches copyright or violates any law, please contact openaccess@qub.ac.uk. 
Potentially inappropriate prescribing among people with dementia in primary care: a retrospective cross-sectional study using the

\section{Enhanced Prescribing Database}

\section{Running title}

Potentially inappropriate prescribing in dementia

\section{Authors}

Heather E. Barry ${ }^{a}$, Janine A. Cooper ${ }^{a}$, Cristín Ryan ${ }^{a, b}$, A. Peter Passmore ${ }^{c, d}$, A. Louise Robinson ${ }^{e}$, Gerard J. Molloy ${ }^{f}$, Carmel M. Darcy ${ }^{\mathrm{g}}$, Hilary Buchanan ${ }^{\mathrm{h}}$, Carmel M. Hughes ${ }^{\mathrm{a}}$

\section{Affiliations}

${ }^{a}$ School of Pharmacy, Queen's University Belfast, Belfast, Northern Ireland, UK

${ }^{b}$ School of Pharmacy, Royal College of Surgeons in Ireland, Dublin, Ireland

'Centre for Public Health, Queen's University Belfast, Belfast, Northern Ireland, UK

${ }^{\mathrm{d} B e l f a s t}$ Health \& Social Care Trust, Belfast, UK

eInstitute for Ageing and Health, Newcastle University, UK

fSchool of Psychology, National University of Ireland, Galway, Ireland

gWestern Health \& Social Care Trust, Londonderry, UK

hUnspecified, Belfast, UK

*Corresponding author

Professor Carmel M. Hughes

Clinical and Practice Research Group, School of Pharmacy, Queen's University Belfast, Medical Biology Centre, 97 Lisburn Road, Belfast, BT9 7BL, Northern Ireland, UK

T: +44 (0)289097 2147

F: +44 (0)289024 7794

E: c.hughes@qub.ac.uk 


\section{Abstract}

Background Little is known about prescribing appropriateness for community-dwelling people with dementia (PWD).

Objective To estimate potentially inappropriate prescribing (PIP) prevalence among PWD in primary care in Northern Ireland, and to investigate associations between PIP and polypharmacy, age and gender.

Methods A retrospective cross-sectional study was conducted, using data from the Enhanced Prescribing Database. Patients were eligible if a medicine indicated for dementia management was dispensed to them during $01 / 01 / 2013-31 / 12 / 2013$. Polypharmacy was indicated by use of $\geq 4$ repeat medications from different drug groups. A subset of the Screening Tool of Older Persons Potentially Inappropriate Prescriptions (STOPP) criteria, comprising 36 indicators, was applied to the dataset. Overall prevalence of PIP and the prevalence per each STOPP criterion was calculated as a proportion of all eligible persons in the dataset. Logistic regression was used to investigate associations between PIP, polypharmacy, age and gender.

Results The study population comprised 6826 patients. Polypharmacy was observed in $81.5 \%$ ( $n=5564)$ of patients. PIP prevalence during the study period was $64.4 \%$ (95\% Cl $63.2-65.5$; $n=4393$ ). The most common instance of PIP was the use of anticholinergic/antimuscarinic medications ( $n=1718 ; 25.2 \% ; 95 \% \mathrm{Cl} 24.2-26.2$ ). In multivariable analyses, both polypharmacy and gender (being female) were associated with PIP, with odds ratios of $7.6(95 \% \mathrm{Cl} 6.6-8.7)$ and 1.3 $(95 \% \mathrm{Cl} 1.2-1.4)$ respectively. No association was observed between PIP and age, after adjustments for gender and polypharmacy.

Conclusion This study identified a high prevalence of PIP in community-dwelling PWD. Future interventions may need to focus on certain therapeutic categories and polypharmacy.

Keywords: Dementia; pharmacoepidemiology; inappropriate prescribing; polypharmacy; primary health care 


\section{INTRODUCTION}

Demographic ageing is a process taking place worldwide, and is reflective of the major advancements in healthcare over the last century. Consequently, prescribing for older people, conventionally defined as those aged 65 years and over, is becoming an increasingly important aspect of clinical care, and one that requires prudent consideration from prescribers [1]. The presence, and subsequent management of, multiple morbidities in older patients will often result in polypharmacy [2], which has frequently been described as the concurrent use of four or more medications $[3,4]$. Use of ten or more medications has been termed 'excessive polypharmacy' [5]. While polypharmacy may be appropriate and therapeutically beneficial where a number of medications are clinically indicated (such as patients with complex or multiple conditions) [2], it is known to be a risk factor for adverse drug events (ADEs), drug-drug and drug-disease interactions, and potentially inappropriate prescribing (PIP) $[3,4,6]$. PIP refers to the use of medicines that introduce a greater risk of adverse drug-related events where a safer, as effective alternative is available to treat the same condition [6]. PIP is associated with increases in negative outcomes such as morbidity, ADEs, hospitalisations and mortality $[7,8]$, and is reported to be common amongst older people [9-11]. A myriad of tools have been developed to identify inappropriate prescribing [2, 7]. The recently updated Screening Tool of Older Person's Prescriptions (STOPP) criteria is a screening tool comprising 80 clinically significant criteria for PIP in older people, primarily organised by physiological system, validated by a Europe-wide Delphi consensus panel [12]. These evidencebased criteria take drug-drug and drug-disease interactions, drug doses, duration of treatment, and clinical effectiveness into consideration when determining the appropriateness of the prescribed treatments. Each criterion is accompanied by a concise, evidence-based explanation as to why the prescribing practice is potentially inappropriate. The STOPP criteria have been extensively validated for use in the United Kingdom (UK) setting [2].

Consideration of the appropriateness of prescribing for people with dementia (PWD) is particularly important due to the unique medication needs that this vulnerable population have in comparison to the rest of the older population. The presence of other comorbidities and complex medication regimens with possible psychoactive drug use, together with deficits in cognition and communication and diminishing decision-making capacity, generate challenges with medication management, particularly adherence [13]. Such issues may also influence doctors' prescribing behaviour and the quality of chronic illness management [14, 15]. For example, Wood-Mitchell et al. reported that psychiatrists in England felt under pressure to prescribe for PWD experiencing behavioural and psychological symptoms and did not always adopt an evidence-based approach to 
prescribing activity [13]. Whilst a number of studies have reported on appropriateness of prescribing for PWD, these tend to focus on dementia patients living in long-term care facilities $[16,17]$, those at the end of life $[18,19]$, or those prescribed antipsychotic medications [20, 21]. Less attention has been paid to PWD living in their own homes within the primary healthcare setting. Studies that have specifically investigated inappropriate medication use within this dementia patient population have been small in size and relied on patient or caregiver reports of drug use [22-26].

An assessment of the appropriateness of prescribing for PWD, especially those managed within the primary healthcare setting, may help to identify a population likely to benefit from interventions to optimise prescribing practices. Therefore, the aim of this pharmacoepidemiological study was to estimate the prevalence of PIP among PWD in primary care in Northern Ireland ( $\mathrm{NI}$ ), by applying a subset of the STOPP criteria to a prescribing database. We also sought to explore the association between PIP and factors such as polypharmacy, age and gender, to more precisely characterise those with dementia who might be at risk of PIP.

\section{MATERIALS AND METHODS}

Setting

Northern Ireland is part of the UK, has a population of $\sim 1.7$ million, and primary healthcare is delivered through $\sim 330$ general practices. Healthcare in $\mathrm{NI}$ is provided under the UK's National Health Service (NHS), where health and social care is publicly funded through central taxation and is free-of-charge at the point of need to all citizens. Unlike some other countries in the UK (namely England and Scotland), prescriptions (and therefore all medications) have been free in $\mathrm{NI}$ since prescription charges were phased out in 2010.

\section{Data source}

Data were extracted from the Enhanced Prescribing Database (EPD), which securely holds information on drugs prescribed and subsequently dispensed to patients in primary care in NI. The EPD does not contain data relating to prescribing in the hospital setting or over-the-counter (OTC) medication use. Once prescriptions have been dispensed by community pharmacies, they are forwarded to the Health and Social Care (HSC) Business Services Organisation (BSO) at the end of each month for reimbursement. Computer-generated prescriptions contain a unique twodimensional barcode which is scanned by the BSO during the reimbursement process. This barcode links a patient's Health and Social Care Number with details of their prescribed medication and prescriber. Once this information is scanned by the BSO, it is held in a secure database, the EPD. At 
present, approximately $85-90 \%$ of all prescriptions forwarded to the BSO result in data of research standard, which has helped to generate a central database of approximately 1.9 million patients in NI [9]. Diagnoses and other clinical information are not recorded in the EPD.

\section{Study design and population}

This was a retrospective, cross-sectional study using data from the EPD. Ethical approval was received from the NHS Research Ethics Committee London - City Road and Hampstead (14/LO/1891). Study participants were identified by a computerised search of the EPD, which was conducted by BSO data custodians. The study population comprised all individuals in the EPD who were dispensed a drug for the management of dementia (donepezil, galantamine, rivastigmine, memantine) during the study period 01/01/2013 - 31/12/2013. These drugs were used as proxy measures for diagnosis of dementia in the absence of clinical information about individuals. Patients in the EPD who entered a care home on or before 31/12/2013 were excluded, as were patients who left $\mathrm{NI}$ or died during the study period. In order to apply certain STOPP criteria, all patients were required to have at least three months of lead-in data prior to $01 / 01 / 2013$, to ascertain long-term use of certain medications. All data were anonymised and the research team had no access to any patient identifiable data.

The final version of the dataset that was available to the research team included a unique patient identifier and information on patients' age (in years), gender, the month and year in which a prescription was scanned by the BSO, and data on all items prescribed (such as the drug name, strength, quantity, and date of issue) during the study period.

\section{Exposures}

Thirty-eight of the 80 STOPP indicators were deemed suitable by the research team for application to the EPD dataset in the absence of clinical or diagnostic information. Some indicators could not be applied due to the absence of clinical or diagnostic data and were therefore excluded. For example, 'aldosterone antagonists with concurrent potassium-conserving drugs without monitoring of serum potassium' could not be operationalised due to the absence of data on biochemical monitoring, and therefore, was not included. For some criteria, prescription drugs for the treatment of certain disease conditions were identified in the EPD dataset and used as proxies for diagnosis, where possible, such as for glaucoma and gout (Supplementary table 1). This method has been used in other studies $[8,9]$. During analysis, the following two STOPP indicators were unable to be operationalised due to lack of long-term prescribing data: 'long-term use of NSAID for symptom relief 
of osteoarthritis where paracetamol has already been tried' and 'long-term NSAID or colchicine for chronic treatment of gout where there is no contraindication to a xanthine-oxidase inhibitor'. Therefore, a total of 36 STOPP indicators were applied to the final dataset.

Data on drug use were extracted using British National Formulary (a standard drug reference text used in the UK) codes [1]. Patients were categorised into those who received a STOPP criteria drug or drug combination. STOPP criteria which specified a particular duration, such as 'benzodiazepines for $\geq 4$ weeks', were assessed by identifying individuals who used the drugs for durations exceeding these 'appropriate' thresholds within the study period (using the month a prescription was scanned by the BSO). STOPP criteria which specified a particular dosage not to be exceeded, such as 'oral elemental iron doses greater than $200 \mathrm{mg}$ daily', were evaluated by calculating the number of daily defined doses (DDDs) for each recipient using the strength and quantity of the dispensed medication for each prescription.

The total number of prescriptions dispensed for each different drug group (according to BNF code) was calculated for each individual, during the one year study period. A 'repeat medication' was defined as one for which the patient received three or more prescriptions for that agent in the study period. Polypharmacy was examined by the use of four or more repeat medications from different drug groups.

\section{Outcomes}

The primary outcome was the overall prevalence of PIP in PWD in primary care in $\mathrm{NI}$ in 2013, according to a subset of the STOPP criteria. Secondary outcomes measures were: (i) the prevalence of PIP per individual STOPP criterion, and (ii) the association between PIP and polypharmacy, gender, and age group.

\section{Statistical analysis}

The overall prevalence of PIP in the study population and the prevalence per individual STOPP criterion in 2013 (the study period) were calculated as a proportion of all eligible persons in the dataset, and reported as percentage estimate and 95\% confidence intervals $(\mathrm{Cl})$. Adjusted logistic regression analyses were used to calculate odds ratios $(\mathrm{OR})$ and $95 \% \mathrm{Cl}$ to investigate the association between any (versus no) PIP and polypharmacy (categorised as 0-3 versus $\geq 4$ repeat drug classes), age group ( $\leq 44,45-64,65-84, \geq 85$ years) and gender (male, female). There were no missing data for 
the variables of interest. Analyses were performed using STATA SE v13 (StataCorp, College Station, TX, USA).

\section{RESULTS}

Characteristics of the study population

For the study period, 6826 persons identified in the EPD were eligible for inclusion in the study (Table 1). Of these, approximately two-thirds were female $(n=4393,64.4 \%)$, with a mean age of 79.6 [standard deviation (SD) \pm 8.0 ] years. Patients were taking a mean number of 6.8 (SD \pm 3.5 ) repeat medications. Over three-quarters of patients $(n=5564,81.5 \%)$ were receiving four or more repeat medications (the definition of polypharmacy adopted for this study), whilst the use of ten or more repeat medications was observed in one-fifth of patients ( $n=1427,20.9 \%)$.

[Insert Table 1 here]

\section{Overall prevalence of PIP in 2013}

The overall prevalence of PIP in the study period, according to the 36 STOPP indicators that were applied to the dataset, was $64.4 \%(95 \% \mathrm{Cl} 63.2-65.5)(n=4393)$. Over one-fifth of the population [ $n=1571,23.0 \%(95 \% \mathrm{Cl} 22.0-24.0)]$ was prescribed one potentially inappropriate medication, 1141 patients $[16.7 \%(95 \% \mathrm{Cl} 15.8$ - 17.6)] were prescribed two potentially inappropriate medications, and 1681 patients [24.6\% $(95 \% \mathrm{Cl} 23.6-25.7)$ ] were prescribed three potentially inappropriate medications.

\section{Prevalence of PIP in 2013 according to individual STOPP criteria}

Table 2 describes the prevalence for each STOPP criterion. The most common instance of PIP was the use of anticholinergic/antimuscarinic medications ( $n=1718,25.2 \%)$. The second most frequently prescribed potentially inappropriate medicines were proton pump inhibitors (PPIs) at full therapeutic dosage for $>8$ weeks ( $n=1561,22.9 \%$ ), followed by acetylcholinesterase inhibitors with concurrent treatment with drugs that reduce heart rate $(n=1276,18.7 \%)$, benzodiazepines for $\geq 4$ weeks $(n=777,11.4 \%)$, and use of regular opioids without concomitant laxative $(n=715,10.5 \%)$. Duplication of therapy within drug classes was most frequently observed with opioid analgesics $(n=346,5.1 \%)$ and benzodiazepines ( $n=239,3.5 \%)$. Many other STOPP criteria had a prevalence less than $1.0 \%$, such as 'thiazide diuretic with a history of gout' and 'phenothiazines as first-line treatment, since safer and more efficacious alternatives exist'. 
[Insert Table 2 here]

\section{Factors associated with PIP}

Univariate logistic regression confirmed that polypharmacy, age and gender were significantly associated with PIP (Table 3). A strong association between PIP and polypharmacy was observed. Those receiving four or more repeat medications were seven and a half times more likely to be exposed to PIP compared to those on zero to three repeat medications (adjusted OR 7.6, 95\% $\mathrm{Cl} 6.6$ - 8.7). PIP was more likely to occur in females than in males after adjusting for age and polypharmacy (adjusted OR 1.3, 95\% Cl $1.2-1.4$ ). No association was observed between PIP and age after adjustments for gender and polypharmacy.

[Insert Table 3 here]

\section{DISCUSSION}

Findings

Based on the data from a comprehensive dispensing database of 6826 dementia patients in $\mathrm{NI}$, we found that both polypharmacy and PIP were prevalent among this community-dwelling patient population during 2013. PIP occurred in nearly two-thirds of the population (64.4\%), according to the subset of STOPP criteria applied. The most commonly prescribed potentially inappropriate medicines were anticholinergic/antimuscarinic medications, followed by PPIs at maximum therapeutic dosage for $>8$ weeks, acetylcholinesterase inhibitors with concurrent treatment with drugs that reduce heart rate, and benzodiazepines for $\geq 4$ weeks. Polypharmacy and gender were significantly associated with PIP. Age was not associated with PIP.

To our knowledge, this is one of the first studies to apply the STOPP criteria to a large prescribing database in order to ascertain the prevalence of PIP amongst community-dwelling dementia patients. Previous studies have reported a lower prevalence of potentially inappropriate medication use (between $15 \%$ and $47 \%$ ) among community-dwelling dementia patients, as reported using either the Beers criteria or PRISCUS list (a tool developed for use in Germany) [22-26]. The prevalence of PIP in our study was nearly double that reported by Bradley et al. who investigated PIP in older people (aged $\geq 70$ years) in NI using the STOPP criteria, but whose methodology did not focus specifically on PWD [10]. 
In addition, we found that the prevalence of polypharmacy, as defined by the use of four or more repeat medications, was high amongst this patient population (81.5\%). Again, this is difficult to directly compare with previous studies which have used different numeric thresholds to define polypharmacy in their study populations. However, this finding is much greater than that reported by Montastruc et al. [26] and Lau et al. [23] who reported polypharmacy ( $\geq 5$ medications) in $43 \%$ and $52 \%$ respectively of community-dwelling patients with dementia. A high prevalence of polypharmacy is unsurprising in PWD, as often this patient population will suffer from a number of comorbidities due to their increasing age and frailty [27]. Whilst patients in the current study population ranged in age from 34 to 100 years, they had a mean age of 79.6 years, and would therefore be expected to be receiving a number of different medications for comorbid conditions. There has been discussion within the literature about reducing reliance on numeric thresholds for polypharmacy and considering instead the appropriateness of polypharmacy, taking into account the fact that the use of 'many drugs' may be necessary for those with multimorbidities $[2,28]$.

This study revealed a number of instances of PIP; some of these, such as the use of PPIs at full therapeutic dosage for $>8$ weeks and benzodiazepines for $\geq 4$ weeks, are unsurprising and are consistent with findings reported in other studies exploring PIP amongst older people $[10,11]$ and PWD in care homes [17]. The prescribing of anticholinergic/antimuscarinic medications in our study population, received by one-quarter of patients (25.2\%), was a concerning finding. The use of these drugs in PWD is not recommended due to their association with decline in both physical and cognitive function [29], and yet other studies have found similarly prevalent use of anticholinergics in dementia patients $[24,26,30]$. A number of tools have been developed to measure the anticholinergic drug burden, such as the validated Anticholinergic Cognitive Burden Scale [31]. The availability of such tools to clinicians could prove invaluable during an in-depth medication review with dementia patients, and may help them to change patients to alternative drugs with a lower anticholinergic burden. In some situations, non-pharmacological measures could be used as alternatives to prescribing anticholinergic medications, for example scheduling regular toilet breaks and making dietary modifications instead of using bladder antispasmodics [32].

\section{Practice implications}

In our study, the high prevalence of both polypharmacy and PIP could serve as an indicator that review of these patients is required to fully assess the appropriateness of the medication regimens used, particularly considering the strong relationship we observed between polypharmacy and PIP, which has been reported previously [9-11, 17, 22-23, 25-26]. This study also revealed that PIP among 
community-dwelling dementia patients was associated with female gender, but not age. Again, these relationships have been reported elsewhere $[9-11,25-26]$ and would be of assistance to clinicians identifying patients at risk of PIP. These associations may be useful in generating hypotheses which could be explored in other datasets. Consideration of PIP, polypharmacy and gender could be incorporated into clinicians' prescribing systems in order to alert them to such highrisk patients and potentially inappropriate medication combinations [33]. Medication review is just one component of medicines optimisation, employing a patient-focused and person-centred approach which ensures that patients obtain the best possible outcomes from their medicines [34]. Often GPs find it difficult to incorporate robust medication review into consultations due to time constraints; opportunity therefore exists for other healthcare professionals such as community pharmacists and nurses to assist with this and examples of such interventions in a primary care setting have been reported in the literature [35-37]. With respect to pharmacists, the role of the GP practice-based pharmacist is expanding and a pilot scheme will be launched in the UK during 2016 [38]. These pharmacists will be ideally placed to assist with medication review of patients and will also be able to identify patients at high risk from PIP and potentially inappropriate medications.

Deprescribing is another way in which inappropriate medication use and polypharmacy may be managed [39], and could prove to be a useful intervention in this particular patient population. For example, 'drug holidays' (where medication is stopped for a trial period to assess effectiveness of treatment and/or remission of symptoms [40]) could be advocated for anticholinergic medications, such as those for urinary incontinence. Deprescribing is an emerging area within the scientific literature and it has been acknowledged that a wider evidence-base is needed to support such an approach [41-44]. It has been reported that deprescribing may be particularly complicated in PWD due to their diminishing capacity and involvement in decision-making about their medicines, and difficulties with communication and understanding [45]. Reeve et al. have called for further research into the beliefs and preferences of dementia patients and their carers in order to better understand how deprescribing can be of optimal benefit to this patient population [45].

\section{Strengths and limitations}

This is one of the largest epidemiological studies to use a prescription-based database to estimate PIP amongst community-dwelling dementia patients. The EPD holds information on all prescriptions dispensed in community pharmacies in $\mathrm{NI}$, and the high scan rate of prescriptions has generated a reliable database of great use to researchers. Although we have confidence in the generalisability of the results to the wider dementia patient population within $\mathrm{NI}$, there are a number of 
methodological limitations which may limit generalisability of the findings to other settings. The lack of clinical information within the EPD, notably diagnostic data, means there could be an underestimation of the prevalence of patients with dementia. We had to identify patients who had received one of four drugs used in the management of dementia, using these medications as a proxy for a dementia diagnosis. These drugs are licensed for the treatment of mild to moderate dementia in Alzheimer's disease (donepezil, galantamine), moderate to severe dementia in Alzheimer's disease (memantine) or mild to moderate dementia in Parkinson's disease (rivastigmine) [1]. Whilst this may have excluded those with dementia of different aetiologies or those with severe cases in whom the medication had been stopped, we had no alternative means of identifying the patient population for inclusion in the study in the absence of diagnostic information. In addition, the lack of clinical data within the EPD only allowed us to apply a subset of the STOPP criteria and some diagnoses had to be determined using drug proxies, an analytical approach which has been used previously $[9,10,46]$. Therefore some instances of PIP identified within this study may not be clinically relevant, and clinicians must ensure that prescribing decisions are also based upon their clinical and personal knowledge of each patient. A set of explicit prescribing criteria for dementia is under development in Australia [47] and may be useful to researchers carrying out similar epidemiological studies in the future. The EPD was chosen for its relevance to the NI setting over other databases such as the Clinical Practice Research Datalink (CPRD), which is not representative of NI prescribing data [48]. Other limitations of using drug dispensing data is that patient adherence to medication is assumed. Use of over-the-counter (OTC) medications purchased without a prescription is not accounted for, which may under-estimate or over-estimate PIP prevalence and use of anticholinergic/antimuscarinic medications in particular, due to the anticholinergic effect of many OTC sleeping aids and antihistamines.

Despite these limitations, polypharmacy and PIP are prevalent among community-dwelling dementia populations; female patients and those receiving four or more medications may be at particular risk from inappropriate prescribing practices. This study has added to the limited body of epidemiological work undertaken with the community-dwelling dementia population as its focus, and may assist clinicians to identify 'at-risk' dementia patients in need of medication review within the primary care setting. Further pharmacological studies should be undertaken to validate the findings from the present study in other settings, such as the rest of the UK or Europe. Future work should also focus on exploring GPs' prescribing behaviours for these patients to further understand the factors influencing prescribing decisions. 


\section{ACKNOWLEDGEMENTS}

The authors wish to thank the staff at the HSC Business Services Organisation, Information and Registration Unit for supplying data from the Enhanced Prescribing Database and providing technical support throughout the study. This work was funded by the HSC Research \& Development Division of the Public Health Agency in Northern Ireland and The Atlantic Philanthropies (Ref: COM/5020/14). The funders had no role in the design or conduct of the study; in the analysis and interpretation of the data; or in the preparation or approval of the manuscript.

\section{REFERENCES}

[1] Joint Formulary Committee (2015) British National Formulary, 69 ${ }^{\text {th }}$ ed, BMJ Group and Pharmaceutical Press, London, UK

[2] Duerden M, Avery T, Payne R (2013) Polypharmacy and medicines optimisation: making it safe and sound, The King's Fund, London, UK

[3] Rollason V, Vogt N (2003) Reduction of polypharmacy in the elderly: a systematic review of the role of the pharmacist. Drugs \& Aging 20, 813-832.

[4] Patterson SM, Cadogan CA, Kerse N, Cardwell CR, Bradley MC, Ryan C, Hughes CM (2014) Interventions to improve the appropriate use of polypharmacy for older people. Cochrane Database Syst Rev 10, CD008165.

[5] Jyrkka J, Enlund H, Korhonen MJ, Sulkava R, Hartikainen S (2009) Patterns of drug use and factors associated with polypharmacy and excessive polypharmacy in elderly persons. Results of the Kuopio 75+ study: a cross-sectional analysis. Drugs Aging 26, 493-503

[6] O'Mahony D, Gallagher PF (2008) Inappropriate prescribing in the older population: need for new criteria. Age Ageing 37, 138-141.

[7] Spinewine A, Schmader KE, Barber N, Hughes C, Lapane KL, Swine C, Hanlon IT (2007) Appropriate prescribing in elderly people: how well can it be measured and optimised? Lancet 370, 173-184

[8] Hamilton H, Gallagher P, Ryan C, Byrne S, O'Mahony D (2011) Potentially inappropriate medications defined by STOPP criteria and the risk of adverse drug events in older hospitalised patients. Arch Int Med 171, 1013-1019.

[9] Cahir C, Fahey T, Teeling M, Teljeur C, Feely J, Bennett K (2010) Potentially inappropriate prescribing and cost outcomes for older people: a national population study. Br J Clin Pharmacol 69, 543-552.

[10] Bradley MC, Fahey T, Cahir C, Bennett K, O'Reilly D, Parsons C, Hughes CM (2012) Potentially inappropriate prescribing and cost outcomes for older people: a cross-sectional study using the Northern Ireland Enhanced Prescribing Database. Eur J Clin Pharmacol 68, 1425-1433.

[11] Bradley MC, Motterlini N, Padmanabhan S, Cahir C, Williams T, Fahey T, Hughes CM (2014) Potentially inappropriate prescribing among older people in the United Kingdom. BMC Geriatr 14, 72.

[12] O'Mahony D, O'Sullivan D, Byrne S, O'Connor MN, Ryan C, Gallagher P (2015) STOPP/START criteria for potentially inappropriate prescribing in older people: version 2. Age Ageing 44, 213-218. 
[13] Maidment ID, Fox C, Boustani M, Katona C (2012) Medication management - the missing link in dementia interventions. Int J Geriatr Psychiatr 27, 439-442.

[14] Wood-Mitchell A, James IA, Waterworth A, Swann A, Ballard C (2008) Factors influencing the prescribing of medications by old age psychiatrists for behavioural and psychological symptoms of dementia: a qualitative study. Age Ageing 37, 547-552.

[15] Imfeld P, Brauchli Pernus YB, Jick SS, Meier CR (2013) Epidemiology, co-morbidities and medication use of patients with Alzheimer's disease or vascular dementia in the UK. J Alzheimers Dis 35, 565-573.

[16] Zuckerman IH, Hernandez JJ, Gruber-Baldini AL, Hebel JR, Stuart B, Zimmerman S, Magaziner J (2005) Potentially inappropriate prescribing before and after nursing home admission among patients with and without dementia. Am J Geriatr Pharmacother 3, 246-254

[17] Parsons C, Johnston S, Mathie E, Baron N, Machen I, Amador S, Goodman C (2012) Potentially inappropriate prescribing in older people with dementia in care homes. Drugs Aging 29, 143-155.

[18] Parsons C, Hughes CM, Passmore AP, Lapane KL (2010) Withholding, discontinuing, and withdrawing medications in dementia patients at the end of life: a neglected problem in the disadvantaged dying? Drugs Aging 27, 435-449.

[19] Parsons C, McCorry N, Murphy K, Byrne S, O'Sullivan D, O’Mahony D, Passmore P, Patterson S, Hughes C (2014) Assessment of factors that influence physician decision making regarding medication use in patients with dementia at the end of life. Int J Geriatr Psychiatr 29, 281-290.

[20] Guthrie B, Clark SA, McCowan C (2010) The burden of antipsychotic drug prescribing in people with dementia: a population database study. Age Ageing 39, 637-642.

[21] Monette J, Monette M, Sourial N, Vandal AC, Wolfson C, Champoux N, Fletcher J, Savoie ML (2013) Effect of an interdisciplinary educational program on antipsychotic prescribing among residents with dementia in two long-term care centers. J Appl Gerontol 32, 833-854.

[22] Fialová D, Topinková E, Gambassi G, Finne-Soveri H, Jónsson PV, Carpenter I, Schroll M, Onder G, Sørbye LW, Wagner C, Reissigová J, Bernabei R, AdHOC Project Research Group (2005) Potentially inappropriate medication use among elderly home care patients in Europe. JAMA 293, 1348-1358.

[23] Lau DT, Mercaldo ND, Harris AT, Trittschuh E, Shega J, Weintraub S (2010) Polypharmacy and potentially inappropriate medication use among community-dwelling elders with dementia. Alzheimer Dis Assoc Disord 24, 56-63.

[24] Koyama A, Steinman M, Ensrud K, Hillier TA, Yaffe K (2013) Ten-year trajectory of potentially inappropriate medications in very old women: importance of cognitive status. J Am Geriatr Soc 61, 258263.

[25] Fiss T, Thyrian JR, Fendrick K, van den Berg N, Hoffman W (2013) Cognitive impairment in primary ambulatory health care: pharmacotherapy and the use of potentially inappropriate medicine. Int $J$ Geriatr Psychiatry 28, 173-181.

[26] Montastruc F, Gardette V, Cantet C, Piau A, Lapeyre-Mestre M, Vellas B, Montastruc JL, Andrieu S, REAL.FR Group (2013) Potentially inappropriate medication use among patients with Alzheimer disease 
in the REAL.FR cohort: be aware of atropinic and benzodiazepine drugs. Eur J Clin Pharmacol 69, 15891597.

[27] Formiga F, Fort I, Robles MJ, Riu S, Sabartes O, Barranco E, Catena J (2009) Comorbidity and clinical features in elderly patients with dementia: differences according to dementia severity. $J$ Nutr Health Ageing 13, 423-427

[28] Hughes CM, Cooper JA, Ryan C (2013) Going beyond the numbers - a call to redefine polypharmacy. Br J Clin Pharmacol 77, 915-916

[29] Fox C, Smith T, Maidment I, Chan W, Bua N, Myint PK, Boustani M, Kwok CS, Blover M, Koopmans I, Campbell N (2014) Effect of medications with anti-cholinergic properties on cognitive function, delirium, physical function and mortality: a systematic review. Age Ageing 43, 604-615

[30] Sura SD, Carnahan RM, Chen H, Aparasu RR (2013) Prevalence and determinants of anticholinergic medication use in elderly dementia patients. Drugs Aging 30, 837-844

[31] Salahudeen MS, Buffull SB, Nishtala PS (2015) Anticholinergic burden quantified by anticholinergic risk scales and adverse outcomes in older people: a systematic review. BMC Geriatr 15, 31. doi:10.1186/s12877-015-0029-9

[32] Specht JK (2011) Promoting continence in individuals with dementia. J Gerontol Nurs 37, 17-21

[33] Clyne B, Smith SM, Hughes CM, Boland F, Bradley MC, Cooper JA, Fahey T, OPTI-SCRIPT study team (2015) Effectiveness of a multifaceted intervention for potentially inappropriate prescribing in older patients in primary care: a cluster-randomized trial (OPTI-SCRIPT study). Ann Fam Med 13, 545-553

[34] National Institute for Health and Care Excellence (2015) Medicines optimisation: the safe and effective use of medicines to enable the best possible outcomes, https://www.nice.org.uk/guidance/ng5/resources/medicines-optimisation-the-safe-and-effective-useof-medicines-to-enable-the-best-possible-outcomes-51041805253, Accessed 03 December 2015

[35] Zermansky AG, Petty DR, Raynor DK, Freemantle N, Vail A, Lowe CJ (2001) Randomised controlled trial of clinical medication review by a pharmacist of elderly patients receiving repeat prescriptions in general practice. $B M J 323,1340$

[36] Lenaghan E, Holland R, Brooks A (2007) Home-based medication review in a high risk elderly population in primary care - the POLYMED randomised controlled trial. Age Ageing 36, 292-297

[37] Milos V, Rekman E, Bondesson A, Eriksson T, Jakobsson U, Westerlund T, Midlöv P (2013) Improving the quality of pharmacotherapy in elderly primary care patients through medication reviews: a randomised controlled study. Drugs Aging 30, 235-246

[38] NHS England, Health Education England, Royal College of General Practitioners, British Medical Association (2015) Clinical pharmacists in general practice pilot, https://www.england.nhs.uk/commissioning/wp-content/uploads/sites/12/2015/07/clinicalpharmacists-gp-pilot.pdf, Accessed 03 December 2015

[39] Scott IA, Hilmer SN, Reeve E, Potter K, Le Couteur D, Rigby D, Gnjidic D, Del Mar CB, Roughead EE, Page A, Jansen J, Martin JH (2015) Reducing inappropriate polypharmacy: the process of Deprescribing. JAMA Intern Med 175, 827-834 
[40] Howland RH (2009) Medication holidays. J Psychosoc Nurs Ment Health Serv 47: 15-18

[41] Garfinkel D, Zur-Gil S, Ben-Israel J (2007) The war against polypharmacy: a new cost-effective geriatricpalliative approach for improving drug therapy in disabled elderly people. Isr Med Assoc 9, 430-434

[42] Garfinkel D, Mangin D (2010) Feasibility study of a systematic approach for discontinuation of multiple medications in older adults: addressing polypharmacy. Arch Int Med 170, 1648-1654

[43] Scott IA, Gray LC, Martin JH, PIllans PI, Mitchell CA (2013) Deciding when to stop: towards evidencebased prescribing of drugs in older populations. Evid Based Med 18, 121-124

[44] Reeve E, Shakib S, Hendrix I, Roberts MS, Wiese MD (2014) Review of deprescribing processes and development of an evidence-based, patient-centred deprescribing process. Br J Clin Pharmacol 78, 738747

[45] Reeve E, Bell JS, Hilmer SN (2015) Barriers to optimising prescribing and deprescribing in older adults with dementia: a narrative review. Curr Clin Pharmacol 10, 168-177

[46] Cooper JA, Moriarity F, Ryan C, Smith SM, Bennett K, Fahey T, Wallace E, Cahir C, Williams D, Teeling M, Hughes CM (2016) Potentially inappropriate prescribing in two populations with differing socioeconomic profiles: a cross-sectional database using the PROMPT criteria. Eur J Clin Pharmacol, DOI 10.1007/s00228-015-2003-z

[47] Page A, Potter K, Clifford R, McLachlan A, Etherton-Beer C (2015) Prescribing for Australians living with dementia: study protocol using the Delphi technique. BMJ Open 5, e008048. doi:10.1136/bmjopen2015-008048

[48] Herrett E, Gallagher AM, Bhaskaran K, Forbes H, Mathur R, van Staa T, Smeeth L (2015) Data resource profile: Clinical Practice Research Datalink (CPRD). Int J Epidemiol 44, 827-836 


\section{TABLES}

Table 1. Characteristics of the study population in the Enhanced Prescribing Database (EPD) dataset $(n=6826)$

\begin{tabular}{|c|c|c|c|}
\hline Variables & $\begin{array}{l}\text { Prevalence, } n \\
\text { (\%) }\end{array}$ & $\begin{array}{l}\text { Mean } \\
( \pm S D)\end{array}$ & \\
\hline \multicolumn{4}{|l|}{ Gender } \\
\hline Male & $2433(35.6)$ & & \\
\hline Female & $4393(64.4)$ & & \\
\hline Age (years) & & $79.6(8.0)$ & $34-100$ \\
\hline$\leq 44$ & $7(0.1)$ & & \\
\hline $45-64$ & $275(4.0)$ & & \\
\hline $65-84$ & $4582(67.1)$ & & \\
\hline$\geq 85$ & $1962(28.7)$ & & \\
\hline Number of repeat medications & & $6.8(3.5)$ & $1-23$ \\
\hline \multicolumn{4}{|l|}{ Polypharmacy ( $\geq 4$ medications) } \\
\hline Never & $1262(18.5)$ & & \\
\hline Ever & $5564(81.5)$ & & \\
\hline
\end{tabular}


Table 2. Prevalence of potentially inappropriate prescribing in 2013 among 6826 people with dementia in Northern Ireland by individual STOPP criteria

\begin{tabular}{lrr}
\hline Criteria description (potential risk) & Number of & $\%$ of patients \\
& patients & $(95 \% \mathrm{Cl})$
\end{tabular}

Indication of medication

Any drug prescribed beyond the recommended duration,

where treatment duration is well defined

Zopiclone and zolpidem (up to 4 weeks)

573

$8.4(7.8-9.1)$

NSAIDs (up to 3 months)

124

$1.8(1.6-2.2)$

Any duplicate drug class prescription (optimisation of

monotherapy within a single drug class should be observed

prior to considering a new agent)

Opioid analgesics

$5.1(4.6-5.6)$

Benzodiazepines

Stimulant laxatives

SSRIS

Statins

34

$0.5(0.4-0.7)$

Cardiovascular system

Beta-blocker in combination with verapamil or diltiazem (risk

of heart block)

Amiodarone as first-line ${ }^{1}$ antiarrhythmic therapy in

supraventricular tachyarrhythmias ${ }^{2}$ (higher risk of side-effects

than beta-blockers, digoxin, verapamil or diltiazem)

Thiazide diuretic with a history of gout ${ }^{2}$ (gout can be

precipitated by thiazide diuretic)

Phosphodiesterase type-5 inhibitors with concurrent nitrate

therapy for angina ${ }^{2}$ (risk of cardiovascular collapse)

\section{Antiplatelet/Anticoagulant drugs}

Long-term aspirin at doses greater than $150 \mathrm{mg}$ per day

(increased risk of bleeding, no evidence for increased efficacy)

NSAID and vitamin $\mathrm{K}$ antagonist, direct thrombin inhibitor or

factor Xa inhibitors in combination (risk of major

gastrointestinal bleeding)

NSAID with concurrent antiplatelet agent(s) without PPI 
prophylaxis (increased risk of peptic ulcer disease)

Central nervous system and psychotropic drugs

TCAs with dementia, narrow-angle glaucoma, cardiac

conduction abnormalities, prostatism, or prior history of

urinary retention ${ }^{2}$ (risk of worsening these conditions)

Dementia

335

$4.9(4.4-5.5)$

Narrow-angle glaucoma

13

$0.2(0.1-0.3)$

Cardiac conduction abnormalities

$0.04(0.01-0.1)$

Prostatism or prior history of urinary retention

25

$0.4(0.3-0.5)$

Initiation of TCAs as first-line antidepressant treatment

75

$1.1(0.09-1.4)$

(higher risk of adverse drug reactions with TCAs than SSRIs or

SNRIS)

Benzodiazepines for $\geq 4$ weeks (no indication for longer

treatment)

Antipsychotics (other than quetiapine or clozapine) in those

with Parkinsonism or Lewy Body Disease ${ }^{2}$ (risk of severe

extrapyramidal symptoms)

Anticholinergics/antimuscarinics to treat extrapyramidal side-

effects of neuroleptic medications (risk of anticholinergic

toxicity)

Anticholinergics/antimuscarinics in patients with dementia ${ }^{2}$

(risk of exacerbation of cognitive impairment)

Acetylcholinesterase inhibitors with concurrent treatment

with drugs that reduce heart rate such as beta-blockers, digoxin, diltiazem, verapamil (risk of cardiac conduction failure, syncope and injury)

Phenothiazines as first-line treatment, since safer and more

efficacious alternatives exist (phenothiazines are sedative,

have significant antimuscarinic toxicity in older people, with

the exception of prochlorperazine for

nausea/vomiting/vertigo, chlorpromazine for relief of

persistent hiccups and levopromazine as an antiemetic in

palliative care)

First generation antihistamines (safer, less toxic

635

$9.3(8.6-10.0)$ 
antihistamines now widely available)

Gastro-intestinal system

Prochlorperazine or metoclopramide with Parkinsonism² ${ }^{2}$ risk

$0.2(0.1-0.3)$

of exacerbating Parkinsonian symptoms)

PPI for uncomplicated peptic ulcer disease or erosive peptic

ulcer oesophagitis ${ }^{2}$ at full therapeutic dosage for $>8$ weeks

(dose reduction or earlier discontinuation indicated)

Oral elemental iron doses greater than $200 \mathrm{mg}$ daily (no

2

$0.03(0.01-0.1)$

evidence of enhanced iron absorption above these doses)

Respiratory system

Theophylline as monotherapy for COPD ${ }^{2}$ (safer, more effective

alternatives; risk of adverse effects due to narrow therapeutic index)

Systemic corticosteroids instead of inhaled corticosteroids for

maintenance therapy in moderate-severe COPD ${ }^{2}$ (unnecessary

exposure to long-term side-effects of systemic corticosteroids

and effective inhaled therapies are available)

Antimuscarinic bronchodilators with a history of narrow-angle

glaucoma or bladder outflow obstruction ${ }^{2}$ (may exacerbate

glaucoma or cause urinary retention)

Narrow-angle glaucoma

$0.2(0.1-0.3)$

Bladder outflow obstruction

Non-selective beta-blocker with a history of asthma ${ }^{2}$ requiring

treatment (risk of increased bronchospasm)

Benzodiazepines with acute or chronic respiratory failure ${ }^{2}$

6

(risk of exacerbation of respiratory failure)

Musculoskeletal system

NSAID with severe hypertension or severe heart failure ${ }^{2}$ (risk

of exacerbation of hypertension or heart failure)

COX-2 selective NSAIDs with concurrent cardiovascular

disease $^{2}$ (increased risk of myocardial infarction and stroke)

NSAID with concurrent corticosteroids without PPI prophylaxis

(increased risk of peptic ulcer disease)

Urogenital system 
Antimuscarinic drugs with dementia, or chronic cognitive

impairment or narrow-angle glaucoma or chronic prostatism ${ }^{2}$

(risk of increased confusion, acute exacerbation of glaucoma

and urinary retention)

Dementia or chronic cognitive impairment

631

$9.2(8.6-10.0)$

Narrow-angle glaucoma

35

$0.5(0.4-0.7)$

Chronic prostatism

122

$1.8(1.5-2.1)$

Endocrine system

Sulphonylureas with a long duration of action with type 2

2

$0.03(0.01-1.1)$

diabetes mellitus ${ }^{2}$ (risk of prolonged hypoglycaemia)

Thiazolidinediones in patients with heart failure ${ }^{2}$ (risk of

0

0.00 exacerbation of heart failure)

\section{Analgesic drugs}

Use of oral or transdermal strong opioids as first-line therapy

$0.7(0.5-1.0)$

for mild pain (WHO analgesic ladder not observed)

Use of regular ${ }^{3}$ (as distinct from PRN) opioids without

concomitant laxative (risk of severe constipation)

Long-acting opioids without short-acting opioids for

breakthrough pain (risk of persistence of severe pain)

Antimuscarinic/Anticholinergic drug burden

Concomitant use of two or more drugs with

$3.2(2.8-3.6)$

antimuscarinic/anticholinergic properties (risk of increased

antimuscarinic/anticholinergic activity)

STOPP, Screening Tool of Older Persons Potentially Inappropriate Prescriptions; NSAID, non-steroidal anti-inflammatory drug; SSRI, selective serotonin reuptake inhibitor; TCA, tricyclic antidepressant; PPI, proton pump inhibitor; COPD, chronic obstructive pulmonary disease; COX-2, cyclooxygenase-2; WHO, world health organisation; PRN, when required

${ }^{1 ' F i r s t-l i n e ' ~ t h e r a p y ~ w a s ~ d e t e r m i n e d ~ b y ~ e x a m i n i n g ~ p r e s c r i b i n g ~ i n ~ t h e ~ t h r e e ~ m o n t h s ~ p r i o r ~ t o ~ s t a r t i n g ~ t h e ~ d r u g ~ i n ~ q u e s t i o n ~}$ ${ }^{2}$ The use of drugs commonly indicated in certain disease conditions (such as gout, parkinsonism, glaucoma) were identified in the Enhanced prescribing Database (EPD) and used as proxies for diagnosis

${ }^{3} \mathrm{An}$ opioid was defined as being used 'regularly' if a patient had received a prescription for an opioid for three consecutive months 
Table 3. Logistic regression analyses investigating any PIP criteria

\begin{tabular}{lll}
\hline PIP & Unadjusted OR $(95 \% \mathrm{Cl})$ & Adjusted OR $(95 \% \mathrm{Cl})$ \\
\hline Polypharmacy & & 1.0 \\
$\quad$ Never (ref) & 1.0 & $7.6(6.6-8.7)$ \\
$\quad$ Ever & $7.5(6.5-8.6)$ & \\
Gender & 1.0 & 1.0 \\
$\quad$ Male (ref) & $1.2(1.1-1.4)$ & $1.3(1.2-1.4)$ \\
Female & & \\
Age group (years) & 1.0 & 1.0 \\
$\quad \leq 44$ (ref) & $0.6(0.1-3.2)$ & $0.8(0.1-4.6)$ \\
$45-64$ & $0.7(0.1-3.7)$ & $0.7(0.1-4.2)$ \\
$65-84$ & $0.8(0.1-3.9)$ & $0.7(0.1-4.0)$ \\
$\geq 85$ & &
\end{tabular}


Supplementary table 1. List of drugs used as proxies for conditions listed in STOPP criteria

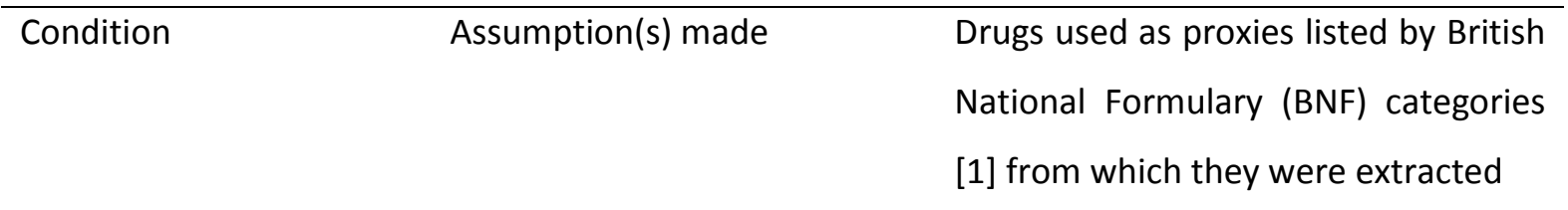

\begin{tabular}{|c|c|c|}
\hline $\begin{array}{l}\text { Supraventricular } \\
\text { tachyarrhythmias }\end{array}$ & $\begin{array}{l}\text { Presence of supraventricular } \\
\text { tachyarrhythmias was } \\
\text { assumed by dispensing of } \\
\text { drug indicated for SVT }\end{array}$ & $\begin{array}{l}\text { 2.1.1 Cardiac glycosides } \\
\text { 2.4 Beta-adrenoceptor blocking } \\
\text { drugs } \\
\text { 2.6.2 Calcium-channel blockers }\end{array}$ \\
\hline Gout & $\begin{array}{l}\text { Presence of gout was } \\
\text { assumed by dispensing of } \\
\text { drug indicated for gout }\end{array}$ & $\begin{array}{l}\text { 10.1.4 Gout and cytotoxic-induced } \\
\text { hyperuricaemia }\end{array}$ \\
\hline Angina & $\begin{array}{l}\text { Criterion states 'concurrent } \\
\text { nitrate therapy for angina' }\end{array}$ & 2.6.1 Nitrates \\
\hline Dementia & $\begin{array}{l}\text { Presence of dementia was } \\
\text { assumed by dispensing of } \\
\text { drug indicated for dementia }\end{array}$ & 4.11 Drugs for dementia \\
\hline Glaucoma & $\begin{array}{l}\text { Presence of glaucoma was } \\
\text { assumed by dispensing of } \\
\text { drug indicated for glaucoma }\end{array}$ & 11.6 Treatment of glaucoma \\
\hline $\begin{array}{l}\text { Cardiac conduction } \\
\text { abnormalities }\end{array}$ & $\begin{array}{l}\text { Presence of cardiac } \\
\text { conduction abnormalities was } \\
\text { assumed by dispensing of } \\
\text { anti-arrhythmic agent }\end{array}$ & 2.3.2 Drugs for arrhythmias \\
\hline $\begin{array}{l}\text { Prostatism or prior } \\
\text { history of urinary } \\
\text { retention or bladder } \\
\text { outflow obstruction }\end{array}$ & $\begin{array}{l}\text { Presence of prostatism and } \\
\text { prior history of urinary } \\
\text { retention was assumed by } \\
\text { dispensing of drugs indicated } \\
\text { for BPH or for urinary } \\
\text { retention }\end{array}$ & $\begin{array}{l}\text { 6.4.2 Male sex hormones and } \\
\text { antagonists } \\
\text { 7.4.1 Drugs for urinary retention }\end{array}$ \\
\hline Parkinsonism & $\begin{array}{l}\text { Presence of Parkinsonism was } \\
\text { assumed by dispensing of } \\
\text { dopaminergic and } \\
\text { antimuscarinic drugs used in } \\
\text { those with Parkinson's }\end{array}$ & $\begin{array}{l}\text { 4.9.1 Dopaminergic drugs used in } \\
\text { Parkinsonism } \\
\text { 4.9.2 Antimuscarinic drugs used in } \\
\text { Parkinsonism }\end{array}$ \\
\hline
\end{tabular}




\begin{tabular}{|c|c|c|}
\hline & disease/Parkinsonism & \\
\hline $\begin{array}{l}\text { Uncomplicated peptic } \\
\text { ulcer disease or erosive } \\
\text { peptic oesophagitis }\end{array}$ & $\begin{array}{l}\text { An assumption was made } \\
\text { that if a PPI was dispensed, it } \\
\text { was being used for these } \\
\text { conditions }\end{array}$ & 1.3.5 Proton Pump Inhibitors \\
\hline Moderate to severe & Presence of moderate-severe & 3.1.1 Adrenoceptor agonists \\
\hline COPD & $\begin{array}{l}\text { COPD was assumed by } \\
\text { dispensing of short-acting } \\
\text { beta }_{2} \text { agonist in combination } \\
\text { with long-acting muscarinic } \\
\text { antagonist, long-acting beta } 2 \\
\text { agonist plus inhaled } \\
\text { corticosteroid }\end{array}$ & $\begin{array}{l}\text { 3.1.2 Antimuscarinic bronchodilators } \\
\text { 3.1.3 Theophylline } \\
\text { 3.1.4 Compound bronchodilator } \\
\text { preparations } \\
\text { 3.2 Corticosteroids }\end{array}$ \\
\hline Asthma & $\begin{array}{l}\text { History of asthma was } \\
\text { assumed by dispensing of } \\
\text { beta2 agonist, inhaled } \\
\text { corticosteroid, leukotriene } \\
\text { receptor antagonist, } \\
\text { theophylline }\end{array}$ & $\begin{array}{l}\text { 3.1.1 Adrenoceptor agonists } \\
\text { 3.1.3 Theophylline } \\
\text { 3.2 Corticosteroids } \\
\text { 3.3.2 Leukotriene receptor } \\
\text { antagonists }\end{array}$ \\
\hline $\begin{array}{l}\text { Acute or chronic } \\
\text { respiratory failure }\end{array}$ & $\begin{array}{l}\text { Respiratory failure was } \\
\text { assumed by dispensing of } \\
\text { oxygen }\end{array}$ & 3.6 Oxygen \\
\hline Severe hypertension & $\begin{array}{l}\text { Presence of severe } \\
\text { hypertension was assumed by } \\
\text { dispensing of ACE inhibitor } \\
\text { (or angiotensin II receptor } \\
\text { blocker) + calcium channel } \\
\text { blocker + thiazide-like diuretic } \\
+ \text { alpha blocker }\end{array}$ & $\begin{array}{l}\text { 2.5.5.1 Angiotensin-converting } \\
\text { enzyme inhibitors } \\
\text { 2.5.5.2 Angiotensin-II receptor } \\
\text { antagonists } \\
\text { 2.5.4 Alpha-adrenoceptor blocking } \\
\text { drugs } \\
\text { 2.2.1 Thiazides and related diuretics } \\
\text { 2.6.2 Calcium-channel blockers }\end{array}$ \\
\hline Severe heart failure & $\begin{array}{l}\text { Presence of severe heart } \\
\text { failure was assumed by } \\
\text { dispensing of ACE inhibitor } \\
\text { (or angiotensin II receptor }\end{array}$ & $\begin{array}{l}\text { 2.5.5.1 Angiotensin-converting } \\
\text { enzyme inhibitors } \\
\text { 2.5.5.2 Angiotensin-II receptor } \\
\text { antagonists }\end{array}$ \\
\hline
\end{tabular}


blocker) + beta-blocker +

candesartan or

spironolactone or eplerenone

Cardiovascular disease

Type 2 diabetes mellitus

Heart failure

Cardiovascular disease was

assumed by dispensing of any

cardiovascular drug, e.g.

diuretics; anti-arrhythmic

drugs; beta-adrenoceptor

blocking drugs; drugs for

hypertension and heart

failure; nitrates, calcium-

channel blockers, and other

antianginal drugs; antiplatelet

drugs; lipid-regulating drugs

Presence of type 2 diabetes

was assumed by dispensing of

biguanides, sulphonylureas or

other antidiabetic drugs

indicated for type 2 diabetes

Presence of heart failure was
2.10 Stable angina, acute coronary syndromes, and fibrinolysis

2.11 Antifibrinolytic drugs and haemostatics

\subsection{Lipid-regulating drugs}

assumed by dispensing of ACE

inhibitor or angiotensin-II

receptor antagonist in

combination with a beta-

blocker licensed for use in

heart failure (bisoprolol,

carvedilol, nebivolol)

\subsubsection{Sulphonylureas}

\subsubsection{Biguanides}

6.1.2.3 Other antidiabetic drugs

\subsubsection{Angiotensin-converting} enzyme inhibitors

2.5.5.2 Angiotensin-II receptor antagonists

2.4 Beta-adrenoceptor blocking drugs 
